\title{
REVIEW
}

\section{Jaws: diversities of gnathological history and temporomandibular joint enterprise}

\author{
Dewey A Nelson, William M Landau
}

Department of

Neurology, Thomas

Jefferson University

Medical College,

Philadelphia,

Pennsylvania, USA

D A Nelson

Section of Neurology, Department of

Medicine, Christiana

Care Health Systems,

Wilmington, Delaware,

USA

D A Nelson

\section{Department of}

Neurology and

Neurological Surgery,

Washington University

School of Medicine, St

Louis, Missouri, USA

W M Landau

Correspondence to: Dr William M Landau, Department of Neurology and Neurological Surgery, Washington University

School of Medicine, 6605,

Euclid Ave, St Louis, MO

63110, USA.

Received 18 February 1999

12 April 1999

Accepted 28 April 1999 and in revised form

Epitome: etymology, epistemology, aetiology, and epidemiology

Since 1887, temporomandibular dysfunction (TMD) has been a clouded subject with a large penumbra and a complex and ever changing nomenclature (table 1). It is described as a primary disease entity involving the temporomandibular joint (TMJ) with the key symptom of pain ranging from aching and burning to sharp and jabbing. Various concepts of the syndrome(s) have interested, confused, angered, and often frightened potential patients. In addition, prolonged disabilities and expensive radical treatments with serious complications are notorious. ${ }^{16}$

The common wisdom is that modern concepts of TMD began with three publications by Costen, an otolaryngologist. ${ }^{1-3}$ However, long before the term TMD originated, pre-Costen authors had already published many of the speculations regarding the disturbed meniscal disc and the associated signs and symptoms that later became known as Costen's syndrome (tables 2, 3). At first, his "new disease," allegedly associated with "bony erosions" of the temporomandibular joint (TMJ) and the tympanic plate of the temporal bone, was heralded and enthusiastically accepted by both dentistry and otolaryngology. But by the next decade, this tidy synthesis was undone by well planned studies and the battered meniscal disc vogue was restored.

Over the past half century, much attention was directed toward defining four "gold standard" diagnostic symptoms and signs of TMD: (1) Facial or jaw pains. (2) Tenderness of the muscles of mastication. (3) Sounds (clicks or pops) that originate in the TMJ, often with jaw

Table 1 Evolution of TMD nomenclature

\begin{tabular}{|c|c|c|}
\hline Year & Named syndrome and references & Abbreviation(s) \\
\hline $1934,1937,1939$ & Costen's (Costen) syndrome ${ }^{123}$ & None \\
\hline 1948 & Temporomandibular joint overclosure ${ }^{4}$ & TMJ \\
\hline 1955 & $\begin{array}{l}\text { TM pain-dysfunction syndrome of } \\
\text { Schwartz }\end{array}$ & PDS, TMPDS \\
\hline 1959 & Temporomandibular joint dysfunction ${ }^{7}$ & TMD \\
\hline 1963 & Temporomandibular syndrome ${ }^{8}$ & TMS \\
\hline 1969 & Myofascial pain dysfunction syndrome ${ }^{9}$ & MPD, MPDS \\
\hline 1973 & Mandibular pain dysfunction syndrome ${ }^{10}$ & MDS \\
\hline 1973 & $\begin{array}{l}\text { Temporomandibular joint pain } \\
\text { dysfunction syndrome }{ }^{11}\end{array}$ & TMJ - PDS \\
\hline 1989 & Mandibular whiplash ${ }^{12}$ & None \\
\hline 1990 & Craniomandibular disorder ${ }^{13}$ & $\mathrm{CMD}$ \\
\hline 1992 & TM pain and dysfunction syndrome ${ }^{14}$ & TMPDS \\
\hline 1993 & TMJ/whiplash ${ }^{15}$ & None \\
\hline
\end{tabular}

deviations. (4) Restricted jaw opening (defined in the adult as opening less than about 40 $\mathrm{mm}){ }^{9}$ Together with these criteria came a flood of diagnostic technology and gadgetry that augmented the practice of TMD clinicians; however, the validity and reliability of these instruments are still unproved.

Dispute concerning nomenclature was the first order of business at the 1991 annual meeting of the Craniomandibular Institute. ${ }^{37}$ The members finally accepted this definition of TMD, also later adopted by the American Academy of Orofacial Pain: ${ }^{38}$ "Temporomandibular disorders is a collective term embracing a number of clinical problems that involve the masticatory musculature, the temporomandibular joints and associated structures, or both." The "clinical problems" cited by this panel of dentists are summarised in tables 2 and 3, and are the reason for writing this review.

Epidemiological surveys of TMD frequency and incidence have exposed the underlying conundrums of definition. ${ }^{38-40}$ Solberg et $a l^{39}$ maintained that $76 \%$ of young adults in this country (about 110 million) have one or more signs of TMD diagnosed during research dental examinations. But $74 \%$ of this cohort are totally unaware of their gnathologic dangers because they are asymptomatic. Epidemiologists estimated that at present, $5 \%-6.7 \%$ of the adult population needs treatment. The average age of this endangered population is 34 years, over $85 \%-90 \%$ of whom are women. The "disease" virtually disappears after age 60, an interesting phenomenon of obvious research potential. McNeill ${ }^{38}$ speculated, “...that older subjects are less bothered by their symptoms." Both clinical and socioeconomic considerations direct neurological interest to the TMD problem that is estimated to consume about 32 billion dollars annually in the United States. ${ }^{40}$

Gnathologic prehistory: archeozoic disc erosion BC (before Costen)

Between 1887 and 1929, surgical meniscectomies began to be performed to relieve TMD pain and jaw locking. ${ }^{17} 192024$ The authors of several postmortem studies ascribed TMJ pain to perforations of the articular disc that were traumatised by backward pressure from the mandibular condyle. ${ }^{191}$ Prentiss, ${ }^{41}$ an anatomist, provided a pre-Model A Ford simile that 
Table 2* Evolution of TMD: clinical symptoms 1887-1956

\begin{tabular}{|c|c|}
\hline Author and year & Symptoms \\
\hline & The pre-Costen era \\
\hline Annandale T $1887^{17}$ & TMJ Pain during chewing, joint fixation pain during chewing, "clicking" type jaw sounds \\
\hline Lanz W $1909^{18}$ & pain during chewing, "clicking" of the jaw \\
\hline Summa R $1918^{19}$ & TMJ Pain, mastication weakness \\
\hline Pringle J $1918^{20}$ & TMJ Pain, locking of the joint \\
\hline Wright WH $1920^{21}$ & TMJ Pain, "traumatic deafness," weakness of deglutition, deafness, tinnitus, mental torpor \\
\hline Monson GS $1921^{22}$ & Weakness of deglutition, deafness, tinnitus, mental torpor \\
\hline Decker JC $1925^{23}$ & TMJ "Grinding and crackling," low pitched tinnitus, deafness \\
\hline Wakeley CPG $1929^{24}$ & TMJ Pain, deafness, vertigo, speech defects, personality changes \\
\hline Goodfriend DJ $1933^{25}$ & $\begin{array}{l}\text { Deafness, vertigo, speech defects, personality changes } \\
\text { The post-Costen era }\end{array}$ \\
\hline Costen JB $1934,1937,1939^{123}$ & $\begin{array}{l}\text { Deafness, stuffy ears at mealtime, snapping noises on chewing, auricular and periauricular pain, low } \\
\text { pitched tinnitus, vertigo, "sinus symptoms," vertex and occipital headache, end of day headache, burning } \\
\text { skin at side of nose, pain and paraesthesiae "in distribution of chorda tympani," pain anterior } 2 / 3 \text { tongue, } \\
\text { trismus, limited TMJ opening }\end{array}$ \\
\hline Riesner SE $1936^{26}$ & "Hearing disturbances" \\
\hline Seaver EP $1937^{27}$ & $\begin{array}{l}\text { "Reflex pain and neuralgic headache" of face, eye, ear, nose, and throat; xerostomia, pruritis and herpes of } \\
\text { external ear canal, stuffiness, tinnitus, vertigo, deafness }\end{array}$ \\
\hline Yule OJ $1937^{28}$ & Facial sagging and deformities from condylar slippage, "personality departures," deafness, tinnitus, vertigo \\
\hline Batson OV $1938^{29}$ & "Costen's syndrome," (also) pharyngeal paraesthesiae and fullness \\
\hline Schopper AF $1938^{30}$ & "Costen's syndrome," (also) TMJ subluxation, "popping jaws" \\
\hline Schuyler CH $1939^{31}$ & Trigeminal neuralgia \\
\hline Dingman RO $1940^{32}$ & TMJ Pain, inefficient chewing \\
\hline Block LS $1947^{33}$ & "Costen (sic) syndrome" \\
\hline Sicher H $1948^{4}$ & Pain in neck and throat referred from arthritic TMJs \\
\hline Kiehn CL $1952^{34}$ & TMJ Crepitus, locking, pain on opening \\
\hline Schwartz LL $1955,1956^{56}$ & Pain in muscles of mastication, tension, anxiety, neuroses \\
\hline
\end{tabular}

*Table 2 is intended only to demonstrate general evolutionary trends of TMD symptoms and may not cite all authors who originally described them. Some of these authors disagreed with the specificity of the symptoms listed.

compared symptoms from a diseased TMJ “... to the result of a runaway when the buggy is destroyed and the individual, entangled in the lines, is bumped over the ground." But Connors $^{42}$ repeated Prentiss' work and concluded just the opposite; the articular discs and soft tissues were neither thinned nor perforated, but rather hypertrophied; and what thinning existed was a congenital variation. Other early workers hypothesised that the tympanic plate of the glenoid fossa was eroded by the mandibular condyle that was forced backward secondary to a "closed bite," the consequence of missing posterior teeth. ${ }^{21}{ }^{23}$ Monson $^{22}$ in 1921 wrote that the condyle "...encroaches upon the external auditory meatus, and often causes a resultant defect in hearing in a degree proportionate to the amount of encroachment." Using dental models and cadaver dissections, but with no anatomical or clinical correlates, Goodfriend ${ }^{25}$ provided a more elaborate story of pathogenesis: "The joint may 'rust in' overnight ...psychological findings demonstrate that there is an association of malocclusions with defective speech. The deepening of the fossa and deformation of the condyle are anatomical alterations which involve the ear and eustachian tube..."

\section{The Costen era: a Camelot age of} authoritarian security (tables 2 and 3 ) In his most often cited paper Costen ${ }^{1}$ described

Table 3* Evolution of TMD: clinical signs 1887-1983

\begin{tabular}{|c|c|}
\hline Author and Year & Signs \\
\hline & The pre-Costen era \\
\hline Annandale T $1887^{17}$ & Joint sounds, reduced jaw opening \\
\hline Lanz W $1909^{18}$ & Inefficient chewing, TMJ pain produced by palpation \\
\hline Summa R $1918^{19}$ & Receding chin with short mandible \\
\hline Pringle J $1918^{20}$ & Malocclusion \\
\hline Wright WH $1920^{21}$ & After bite opening, test for improved hearing using whispered voice, watch, tuning fork \\
\hline Monson GS $1921^{22}$ & $\begin{array}{l}\text { Measure facial dimension from base of nose to tip of chin, examine for facial sagging and short upper lip, detect } \\
\text { for condylar backward thrust or slippage by placing small fingers in ear canals, check for defective swallowing }\end{array}$ \\
\hline Decker JC $1925^{23}$ & $\begin{array}{l}\text { Measure face from anterior nares to symphysis of chin, check hearing using whispered voice and tuning fork } \\
\text { tests, examine ear canals for narrowing and intrusion of condyles, palpate inside ear canals with fingers for } \\
\text { "clicks" during jaw movements, palpate TMJs for "grinding and crackling," examine tympanic membranes for } \\
\text { thickening or dullness }\end{array}$ \\
\hline Wakeley C $1929^{24}$ & "Clicking and crackling" of TMJ \\
\hline Goodfriend W $1933^{25}$ & $\begin{array}{l}\text { Facial measurements, palpate condylar movements } \\
\text { The post-Costen era }\end{array}$ \\
\hline Costen JB $1934^{1}$ & $\begin{array}{l}\text { Examine for: overbite, lateral bite slippage, missing teeth, poorly fitting dentures, deformed mandible, } \\
\text { mandibular condyle dislocation, nystagmus, herpes zoster in ear or mouth, xerostomia, sialorrhoea; search for } \\
\text { TMJ pain during joint palpation; hearing is tested by conversational voice or whisper }\end{array}$ \\
\hline Seaver UP $1937^{27}$ & $\begin{array}{l}\text { Palpate for excessive excursion of condylar head as well as crepitus and tenderness with and without dentures, } \\
\text { examine for lateral deviations of mandible during jaw opening }\end{array}$ \\
\hline Schopper AF $1938^{30}$ & $\begin{array}{l}\text { Examine for worn teeth from tobacco chewing or bruxism, inspect for facial asymmetry, make facial } \\
\text { measurements to rule out receding condyle, examine masticatory muscles for unilateral hypertrophy } \\
\text { accompanied by contralateral atrophy }\end{array}$ \\
\hline Dingman RO $1940^{32}$ & Auscultate TMJ sounds, check for difficulties in mastication and phonation \\
\hline Block LS $1947^{33}$ & $\begin{array}{l}\text { while patient clenches teeth, place fingers in external auditory canal using downward and forward pressure to } \\
\text { detect deviations and erratic movements }\end{array}$ \\
\hline Kiehn CL $1952^{34}$ & Auscultate for TMJ crepitus, palpate for meniscus slippage under local anesthetic \\
\hline Schwartz LL 1955, $1956^{5} 6$ & $\begin{array}{l}\text { Palpate for muscle pain and spasm in muscles of mastication as well as in the posterior cervical, trapezius, and } \\
\text { other nearby muscles }\end{array}$ \\
\hline
\end{tabular}

*Table 3 is intended only to demonstrate general evolutionary trends of TMD signs and may not cite all authors who originally described them. Some of these authors disagreed with the specificity of the signs listed. 
11 patients with symptoms of deafness, tinnitus, and vertigo. Later he added 52 additional cases of deafness or vertigo, and 94 of "neuralgic pain and headache." ${ }^{3}$ These patients also had facial paraesthesiae, glossodynia, and trismus. However, the drawings used to justify his theories of bony erosion and irritation of adjacent nerves were anatomically incorrect (see below). Absent the burden of providing clinical-pathological correlation, he concluded, "The anatomic explanation....is fairly simple....deep erosion leaves only a thin plate between the condyles and durapractically nil...all soft tissues next to the eustachian tube were seen to wrinkle and close the tube firmly, permitting close contact of the condyle with the dura..." ${ }^{1}$ His therapeutic recommendations included insufflation of the eustachian tube, and "opening the bite" by the use of built up dentures, inlays, bridges, biteguards, tongue depressors, and gauze pads clenched between the teeth.

This halcyon epoch was documented by enthusiastic endorsement of Costen supporters for over a decade. ${ }^{26} 28303343$ In 1931, Yule ${ }^{28}$ concluded that TMD could produce personality disturbances and "reflex neurosis." Edmand ${ }^{43}$ noted, "The favorable results obtained from increasing the vertical dimension of the jaws....are now a matter of record. Thus, we are also able to improve the wry physiognomy of a patient whose chin almost touches the tip of his nose." In 1937, Schultz ${ }^{44}$ disapproved of the then traditional method consisting of retracting a wandering condyle with a steel headband or wiring the jaws shut for months. His novel invention was to sclerose the TMJ tissues with injections of sodium psylliate, an over the counter bulk laxative.

Early on, Chor, ${ }^{45}$ a neurologist, cast the first critical gauntlet to challenge Costen. $\mathrm{He}$ cautioned that, "....the alleged [TMJ] syndrome be considered carefully in the light of well established syndromes, or syndrome complexes, which they may resemble...the literature is replete with bald statements and hypotheses...such theories are of little value unless substantiated by experimental facts... as a result of a more critical attitude, a great deal of misguided therapy may be prevented." This admonition was followed by a report by Schuyler ${ }^{31}$ who cautioned concerning complications from "opening the bite" by grinding occlusal surfaces; and constructing onlays, inlays, crowns, and bridges. These dental therapies had deleterious effects from alveolar bone and tooth root absorption accompanied by severe pain, anxiety, bruxism, and weight loss.

Landmark anatomical investigations in the 1940 s finally put Costen's theory to rest. Dingman $^{32}$ stated that his colleagues had examined 16000 skulls at the Smithsonian Institute and found no thinning of the glenoid fossa, including skulls with missing posterior teeth (the latter should have "closed the bite" and therefore stressed the TMJ). Two postmortem studies discovered no perforations of articular discs, no thinning of the tympanic plate of the temporal bone, no bony erosions of the external auditory meatus, and no folding or occlusions of eustachian tubes. ${ }^{46}$ Based on audiometric and anatomical studies, Shapiro and Truex ${ }^{46}$ pointed out that, "If one realises that most patients with overbite and loss of high tones fall into a group in which such ear symptoms are expected, the age factor no longer remains merely an interesting and coincidental observation." Looking back on the Costen era from a 1989 perspective, Bell ${ }^{47}$ wrote, "By viewing the half century since Costen ... the dental profession has come a long way - from a state of nearly total unawareness of the significance of temporomandibular disorders to nearly obsessive concern."

\section{An alternative malady: occlusive disharmony}

During the Costen era, many deviant dentists advocated attainment of "occlusive harmony" by bite adjustments usually accomplished by generous grinding of dental cusps. This seemingly benign practice has remained in the dental armamentarium even though it was proved ineffective in several recent reviews. Seligman and Pullinger ${ }^{48}$ in 1991 concluded, "Controlled studies fail to demonstrate any association between occlusal interferences and TMD signs or symptoms."

\section{Post-Costen era: muscular mechanisms and collateral confusion}

The temporomandibular pain and dysfunction syndrome (PDS or TMPDS, table 1) was the first direct investigative challenge to Costen's joint erosion theory by an organised clinical research programme. The central conceptual conflicts of this new myogenic pain hypothesis were whether the pain was "organic" or "psychogenic."

PSYCHOGENIC JAW MUSCLE TMD

Schwartz, ${ }^{56}$ a dentist, headed a multidisciplinary TMD clinic where over 500 patients were treated. His hypothesis was that TMD symptoms originated in mandibular muscles that went through three pathological phases: (1) Early incoordination of muscles producing joint clicking and recurrent subluxation. (2) A middle phase of limitation of mandibular movements by muscle spasm. (3) A final phase of muscle shortening and fibrosis, often irreversible. Psychogenic causes were the most common. Schwartz wrote, "Psychiatric examinations...disclosed all the group...examined to be highly tense individuals with noticeable oral habits." Early EMG studies supported the concepts of Schwartz; however, later well conceived studies proved surface EMG to be useless. ${ }^{38} 4950$

Over the next 35 years, the Schwartz advocates studied other large TMD cohorts and drew these conclusions: (1) Over $85 \%$ of subjects were women, $80 \%$ of whom have histories of stress, depression, daytime tooth clenching, and nocturnal bruxism. (2) The largest number of patients had other psychogenic disorders, along with atypical pain syndromes and low pain thresholds. (3) Antidepressant medications were far superior 
to placebo or bite guard prostheses. (4) Prognosis was more favourable in those with recent stress and no operations. (5) Psychological counselling gave excellent results. (6) Those examined a year after diagnosis showed $90 \%$ improvement with loss of abnormal jaw sounds in over $80 \%$. (7) Patients with TMD and normal TMJs have higher psychometric scores denoting pain, chronic disability, and depression..$^{51-55}$

In a rigorously structured interview study of 50 chronic patients with TMD in which DSMIII-R psychiatric diagnostic criteria were used, Kinney et $a t^{55}$ discovered the prevalences of psychogenic disease to be two to 10 times higher than those in the general population. The lifelong rate for at least one axis I clinical diagnosis was $86 \%$, and $46 \%$ met the criteria for two or more. In addition to somatoform disorders $(50 \%)$ and somatoform pain $(40 \%)$, more serious axis I conditions identified were: affective disorder (78\%) including major depression $(74 \%)$, anxiety disorders $(24 \%)$, and substance misuse $(30 \%)$. Compared with the lifetime rates just summarised, $46 \%$ had current axis I disorders and the majority major depression. Forty per cent had axis II personality disorders: paranoid $(18 \%)$, obsessivecompulsive $(10 \%)$, borderline $(10 \%)$, and histrionic $(8 \%)$. These are more than twice the prevalences in the general population.

"ORGANIC" JAW MUSCLE TMD

Opponents of the psychogenic theory claimed that "organic" TMJ derangements were the primary sources of pain, muscular spasm, and shortening. In psychometric testing, Patients with TMD had less than expected anxiety, neuroses, and depression; and no correlation was found with parental bonding indices. ${ }^{56}$ The PDS or TMPDS muscle spasm aetiology of Schwartz was challenged by authors of two chapters in a recent review of TMD research. ${ }^{40}$ Lund stated that the "vicious cycle" hypothesis of muscle pain and spasm had no basis in fact, "...neither the originator (Travell) nor her collaborators offered direct proof... The idea that TMD is a single progressive disorder...is the end product of this line of speculation." Rudy and Hussein agreed, stating that psychological myogenic factors alone do not explain TMD.

\section{Return of the meandering meniscus}

From relatively tentative 19 th century speculations, the precept of articular disc disease regained great popularity during the 1950s. Dingman and Moorman ${ }^{57}$ recommended complete resection of the offending articular meniscus. Extending this era of ablative surgery, Henny and Baldridge ${ }^{58}$ introduced the more definitive procedure of amputating condylar heads while leaving the discs intact. They advocated this radical technique because after meniscectomy, “...many patients develop recurrence of symptoms at a later date." Dentists then recommended holding the displaced disc in place by bite guards and bite planes, procedures still in general use. Joint sounds, the most common sign of TMD, are said by many TMD experts to result from disc displacement.
Rinchuse et $a P^{9}$ reported that these sounds ("clicks and pops") existed in 14\%-65\% of the general population, depending on whether or not a stethoscope was used for diagnosis. They concluded that "...there is no conclusive scientific evidence...that a patient with TMJ clicking who has no other symptoms would be better off treated...the pathogenesis and ontogeny of TMJ sounds are not known."

Many reports question the utility of TMJ imaging studies because $30 \%$ of normal people have disc displacements and joint arthrosis (degenerative processes affecting the TMJ) is usually benign. ${ }^{38} 6061$ Postmortem examinations of a total of 140 persons (dental histories unknown) showed that $40 \%-80 \%$ had joint pathology or disc displacements. ${ }^{60}$ The relevance of bony joint arthrosis was also disputed by evidence that patients with TMJ rheumatoid arthritic pathology actually had fewer symptoms than normal subjects. ${ }^{35}$ Alling $^{52}$ stated that symptoms associated with degenerative joint changes in young women tended to clear spontaneously in 2 years.

Surgery to "recapture the articular disc" has been proved unsuccessful because the disc often returns to its original position after surgery; and as summarised above, discs "displaced" anterior to the condyle are usually normal. ${ }^{61}$ Disc replacements using plastic implants were followed by $6 \%-75 \%$ complication rates that included ankylosis, bone necrosis, foreign body reactions, condylar osteophytosis, and osteoarthritis. ${ }^{62}$ In the foreword of a book reviewing TMD research, ${ }^{40}$ Löe described the chronic pain and anguish of patients whose implants failed. One said, "My life hasn't changed, its gone. I feel like a big blob of pain, with big burning hot screws constantly twisting into my skull bone in front of my ears." In the same volume, Laskin and Dolwick concluded, "Although surgery is frequently used...a review of the literature provided little objective evidence regarding the efficacy of most of these procedures."

\section{The test's the thing}

Various early diagnostic aids included an "ear test" to see if the mouth would drop open when a ticking watch was distanced from the ear, insertion of fingers into ear canals to detect "clicks" during jaw movements, eustachian tube insufflation to evaluate vertigo, comparative models of dental occlusion (gnathic orthomorphosos), and trials of cork wedges to predict success of "opening the bite." 22232527 More advanced armamentaria included radiographs of the TMJ using routine, transcranial, oblique views, and laminographic studies, wax casts and dentures to check results, as well as trial appliances and splints. A reawakening of the articular disc theory in the 1950 s spawned a cornucopia of controversial state of the art diagnostic tests. This led to the appointment of two blue ribbon study groups by the Canadian Dental Association ${ }^{49}$ and by the American Dental Association. ${ }^{50}$ Readily proved unreliable were: surface and needle EMG of mastication muscles, CT and MRI of the TMJ, dynamic arthrography, mandibular kinesiography, silent 
period durations, thermography, sonography, electrovibratography, and electrostimulation (TENS) devices.

\section{Mandibular whiplash: litigious profit in the neck kink}

The term "whiplash" was first used in 1928 and became a popular medical term after Gay and Abbott's publication concerning rear end motor vehicle accidents in which the authors mistakenly concluded that the subject's head is initially driven forward. ${ }^{63}$ "Cervical strain" as a cause of TMD was described by Roydhouse ${ }^{64}$ in a short letter to the editor. However, the terms "mandibular whiplash" and "TMJ whiplash" came later (table 1). Lader's 1983 article $^{65}$ was "...written for the purpose of providing insurance companies with an explanation concerning the mechanism by which trauma to the cervical area may result in the development of a temporomandibular joint dysfunction problem." There rapidly followed a large amount of literature in assent to the Roydhouse precepts with only a rare dissent. ${ }^{66}$ During this time frame, several reports claimed that MRI of the TMJ was diagnostic of mandibular or TMJ whiplash; however, such uncontrolled retrospective study series must be judged to have doubtful reliability. ${ }^{367}$

Brooke and Stenn ${ }^{68}$ reported that patients with post-traumatic TMD have a poor prognosis for recovery compared with non-traumatic TMD. The authors stated that: "Reasons for this difference...may be a consequence of litigation and, in addition, may be due to the personality of the patient." Some authors reported that some patients claimed the onset of symptoms days or weeks after the professed whiplash incident with diagnoses and treatment beginning even later. ${ }^{12} 3669$ No pathophysiological explanation has been provided for this magically retarded evolution of the TMJ malady from a region supplied by a luxuriant network of $\mathrm{A}-\delta$ and polymodal $\mathrm{C}$ fibres. ${ }^{70} 71$ Obviously, direct trauma to the jaw region by steering wheel, fist, or bat will produce acute pain and there is no doubt that severe trauma and other pathological processes that disrupt the anatomy of the TMJ can sometimes produce symptoms. Olin, ${ }^{72}$ an oralmaxillofacial surgeon recently affirms, "The onset of signs and symptoms should appear soon after the trauma and should be relevant to the trauma."

Thorough acceleration-deceleration studies on human volunteers concluded that the force of a low velocity extension-flexion injury is less than the forces exerted by normal mastication. ${ }^{73}$ Similar extensive experiments on human subjects sponsored by the Society of Automotive Engineers concluded, “...no jaw motion relative to the cranium was seen for any human subject during rear-end impacts." ${ }^{74} 75$ In 1993, The American Academy of Orofacial Pain published their official opinion of mandibular whiplash, "Thus, the condition of mandibular strain at the time of a motor vehicular accident, without a direct blow to the mandible, resulting in hyperextension of the mandibular capsule, ligaments, and mastica- tory muscles is questionable." ${ }^{38}$ Sceptical neurologists must suspect that "TMJ whiplash" is often a clinical manifestation of malingering.

\section{Extraordinary TMD symptoms and claims}

Clinics and treatment centres for TMD advertise extensively in brochures, flyers, electronic media, symposia, and course summaries as well as in non-peer reviewed periodicals. These inform that serious diverse symptoms from many organ systems can devolve from TMD. Among those listed are: sullen and violent behaviour in preschool children, poor personal image from rounded shoulders, major depression requiring cingulotomy, temporary amnesia, intractable migraine, sagittal suture tenderness, carotid artery ischaemia, bulging erythematous eyes and photosensitivity, abnormal lingual movements and dysphagia, painful chewing and swallowing, laryngitis and chronic cough, scoliosis and tilted pelvis with "short leg," menstrual cramps with bloating and bleeding, etc. There are also remarkable therapeutic claims including cure of infertility by proper jaw alignment, significant improvement in long distance running and football place kicking, heightened IQ scores all the way from retardation to being a gifted student, amelioration of hypertension, etc.

\section{Comments}

A consensus of disbelief is evolving. Turk et $a l^{40}$ declared, "Although TMDs have been reported for over six decades, there is a lack of consensus regarding what constitutes a clinically significant syndrome...Cases and controls are distinguished most readily by reports of pain, pain in response to palpation of muscles, restricted vertical range of motion of the mandible, and clicking jaw sounds...In short, many of the most common presenting symptoms and signs associated with TMD are quite common in asymptomatic individuals...."The failure of TMD to quality as a verifiable science was voiced by Weinberg and Lager ${ }^{76}$ in their study of 138 patients with TMD, "The scientific method cannot be applied to TMD patients because of the impossibility of isolating variables and due to the multicausality of the syndrome." In a treatise describing drug therapy for TMD, Denucci et al" stated, "It is now recognised...that many putative dental and surgical therapies for chronic orofacial pain have not withstood the scientific scrutiny of well controlled clinical trials...it would appear that patients with TMDs have pain not unlike that observed in other chronic pain conditions."

Persistently sceptical neurologists have argued that the TMD is a vaguely defined and overly diagnosed "pseudosyndrome" similar to thoracic outlet syndrome, generalised back pain, and coccydynia. ${ }^{4578} 79$ A critical evolution toward conservatism in the dental literature is summarised in conclusions of the $1996 \mathrm{NIH}$ Technology Assessment Conference: ${ }^{80}$ "There are significant problems with the present diagnostic classification...Consensus has not been developed...including which TMD problems should be treated.... The preponderance of the 
data does not support...any method of initial management.... Moreover, the superiority of such methods to placebo controls and no treatment controls remains undetermined.... Although clinical observation can provide direction, these insights must be followed by rigorous scientific evaluation..."

We have been unable to discover any scientifically valid justification for the concept that symptoms in the region of the jaw joints comprise any more coherent meaningful or useful pathophysiological syndromes(s) or diagnostic entity(ies) than do nondescript bellyache or backache. Most distressing for patients, there are no reliable controlled outcome studies of the undiminished varieties of either traditional or radical therapeutic programmes. The TMD family of labels is reminiscent of other antiquated medical terms such as "chilblain" and "miasma" that now have no utility in rational medical practice. We hope that programmed apoptosis will continue to discipline and constrict this confusing anatomically focused diagnostic nomenclature. We think that practical management of these afflicted patients will be served best by clinicians who are especially competent in the diagnosis and treatment of somatisation disorders, depression, anxiety, and substance misuse, as well as the pathophysiology of chronic pain symptoms.

We thank our colleagues who gave us much professional help and encouragement, even though they may not have always agreed with our conclusions: Robert N Arm, John E Dodes, Herbert L Goldberg, and Myer S Leonard. Special thanks to Leonard who reviewed the manuscript. Medical librarians Christine Chastain-Warheit, Ann Gallagher, Sharon Gannett, Ellen M Justice, Patricia Patterson, Roberta Repetti, and Joan Smith provided many expert literature reviews.

1 Costen JB. A syndrome of ear and sinus symptoms dependent upon disturbed function of the temporomandibula joint. Ann Otol Rhinol Laryngol 1934;43:1-15.

2 Costen JB. Some features of the mandibular articulation as it pertains to medical diagnosis, especially otolaryngology. Fournal of the American Dental Association and Dental Cosmos 1937;24:1507-11.

3 Costen JB. Correlation of $x$ ray findings of the mandibular joint with clinical signs, especially trismus. 7 Am Dent Assoc 1939;26:405-7.

4 Sicher H. Temporomandibular articulation in mandibular overclosure. 7 Am Dent Assoc 1948;36:131-9.

5 Schwartz LL Pain associated with temporomandibular Schwartz LL. Pain associated with
joint. f Am Dent Assoc 1955;51:393-7.

6 Schwartz LL. A temporomandibular joint pain-dysfunction syndrome. $\mathcal{F}$ Chronic Dis 1956;3:284-93.

7 Shore NA. Occlusal equilibration and temporomandibular joint dysfunction. Philadelphia: JB Lippincott, 1959:201-70.

8 Berry DC. Temporomandibular syndrome. $\mathcal{F}$ Prosthet Dent 1963;13:1122-9.

9 Laskin DM. Etiology of the pain-dysfunction syndrome. $f$ Am Dent Assoc 1969;79:147-53.

10 Molin C, Edman G. Schalling D. Psychological studies of patients with mandibular pain dysfunction syndrome. Swed Dent $\mathcal{F} 1973 ; 66: 15-23$.

11 Greene CS. The temporomandibular syndrome. $7 A M A$ 1973;224:622.

12 Mannheimer J, Attanasio R, Cinotti WR, et al. Cervical strain and mandibular whiplash: effects upon the craniomandibula

13 Westling L, Carlsson GE, Helkimo M. Background factors in craniomandibular disorders with special reference to General joint hypermobility, parafunction, and trauma. 7 89-98.

14 Raphael KG, Marbach JJ. A year of chronic TMPDS. f Am Dent Assoc 1992;123:49-55.

15 Moses AJ. Legal Perspectives on TMJ/whiplash. Fournal of Craniomandibular Practice 1993;11:237-40.

16 Weiss, T. Report of the Chairman, United States Senate Human Resources Intergovernmental Relations Subcommittee, One Resources Intergovernmental Relations Subcommittee, One
Hundred Second US Congress, Second Session. Are FDA and NIH ignoring the dangers of TMF (jaw) implants? June 4, NIH ignoring the dangers of TMF (jaw) implants? June 4,
1992:1-373. Washington DC: US Government Printing Office.
17 Annandale T. On displacement of the inter-articular cartilage of the lower jaw and its treatment by operation. cartilage of the low

18 Lanz W. Discitis mandibularis. Zentralbl Chir 1909;36:28991

19 Summa R. The importance of the inter-articular fibrocartilage of the temporo-mandibular articulation. The Dental Cosmos 1918;60:512-14.

20 Pringle JH. Displacement of the mandibular meniscus and its treatment. Brf Surg 1918;6:385-9.

21 Wright WH. Deafness as influenced by malposition of the aws. Fournal of the National Dental Association 1920;7:979-

22 Monson GS. Impaired function as a result of closed bite. Fournal of the National Dental Association 1921;8:833-9.

23 Decker JC. Traumatic deafness as a result of retrusion of the condyles of the mandible (preliminary report). Ann Otol Rhinol Laryngol 1925;34:519-27.

24 Wakeley CPG. The causation and treatment of displaced mandibular cartilage. Lancet 1929 ;ii:543-5.

25 Goodfriend DJ. Symptomatology and treatment of abnormalities of the mandibular articulation. The Dental Cosmos 1933; 75:844-52,947-57,1106-11.

26 Riesner SE. Temporomandibular articulation: its consideration in orthodontic diagnosis. International fournal of Orthodontia and Oral Surgery 1936;22:1-30.

27 Seaver EP Jr. Temporomandibular joint malocclusion and the inner ear: a neuromuscular explanation. Ann Otol Rhinol Laryngol 1937;46:140-9.

28 Yule OJ. Opening the bite. $N Z$ Dent $f$ 1937;33:144-51.

29 Batson OV. The closed bite and related clinical problems. $\mathcal{F}$ Am Dent Assoc 1938;25:1191-6.

30 Schopper AF. Lost vertical dimension; causes and effects; diagnosis and various treatments recommended. Fournal of

31 Schuyler $\mathrm{CH}$. Problems associated with opening the bite which would contraindicate it as a common procedure. $\mathcal{F}$ Am Dent Assoc 1939;26:734-40.

32 Dingman RO. Diagnosis and treatment of lesions of temporomandibular joint. Am f Orthodontics 1940;26:374-90.

33 Block LS. Diagnosis and treatment of disturbances of the temporomandibular joint especially in relation to vertical dimension. $\mathcal{F}$ Am Dent Assoc 1947;34:253-60.

34 Kiehn CL. Meniscectomy for internal derangement of temporomandibular joint. Am F Surg 1952;83:364-73.

35 Ettala-Ylitalo UM, Syrjanen S. Halonen P. Functional disturbances of the masticatory system related to temporomandibular joint involvement by rheumatoid arthritis. $\mathcal{F}$ Oral Rehabil 1987;14:415-27.

36 Schellhas KP. Temporomandibular joint injuries. Radiology 1989;173:211-16.

$37 \mathrm{McNeill} \mathrm{C.} \mathrm{Current} \mathrm{controversies} \mathrm{in} \mathrm{temporomandibular}$ disorders. Proceedings of the Craniomandibular Institute's 10th Annual Squaw Valley Winter Seminar Squaw Valley, CaliforAnnual Squaw Valley Winter Seminar Squaw Valley, California. 17 .

38 McNeill C. Temporomandibular disorders. Guidelines for classification, assessment, and management. Carol Stream, Illinois: Quintessence: 1993:1-141

39 Solberg WK, Woo MW, Houston JB. Prevalence of mandibular dysfunction in young adults. $\mathcal{F}$ Am Dent Assoc 1979;98:25-34.

40 Fricton JR, Dubner R. Advances in pain research and therapy. Vol 21. Orofacial pain and temporomandibular disorders. New York; Raven Press, 1995;xvii-xxi:5-11, 103-15, 145-63, 245-75, 375-86, 405-13.

41 Prentiss HJ. A preliminary report upon the temporomandibular articulation in the human type. The Dental Cosmos 1918;60:505-14.

42 Connors MC. Tissue reactions in temporo-mandibular articulation following loss of teeth. The Dental Cosmos 1925;67:124-35.

43 Edmand PA. Restoring lost vertical dimension. 7 Am Dent Assoc 1938;25:849-60.

44 Schultz LW. A curative treatment for subluxation of the temporomandibular joint or any joint. F Am Dent Assoc 1937;24:1947-50.

45 Chor H. Neurologic aspects of temporo-mandibular disorders. F Am Dent Assoc 1938;25:1033-46.

46 Shapiro HH, Truex RC. The temporomandibular joint and the auditory function. 7 Am Dent Assoc 1943;30:1147-68.

47 Bell WE. Temporomandibular disorders, classification, diagnosis, management, second edition. Chicago: Yearbook Medical, 1989:1-15.

48 Seligman DA, Pullinger AG. The role of functional occlusal relationships in temporomandibular disorders: a review. $\mathcal{f}$ relationships in temporomandibular disorders: a review. $\mathcal{F}$ 79

49 Lund JP, Lavigne G, Feine JS, et al. It's my opinion. The use of electronic devices in the diagnosis and treatment of temporomandibular disorders. Canadian Dental Association 1989;55:749-50

50 Mohl ND, McCall WD, Lund JP, et al. Devices for the diagnosis and treatment of temporomandibular disorders. Parts I-III. Fournal of Prosthetic Dentistry 1990;63:198-201,332$5,472-7$.

51 Brooke RI, Stenn PG, Mothersill KJ. The diagnosis and conservative treatment of myofascial pain dysfunction syndrome. Oral Surg 1977;44:844-52.

52 Alling CC III. The diagnosis of chronic maxillofacial pain. Alabama fournal of Medical Sciences 1982;19:242-6.

53 Malow RM, Olson RE, Greene CS. Myofascial pain dysfunction syndrome: a psychophysiological disorder. In: Golden C, Alcaparras S, Strider F, et al, eds. Applied 
techniques in behavioral medicine. New York: Grune and Stratton, 1981:101-33.

54 Feinmann C, Harris M, Cawley R. Psychogenic facial pain: presentation and treatment. BMF 1984;288:436-8.

55 Kinney RK, Gatchel RJ, Ellis E, et al. Major psychological disorders in chronic TMD patients: implications fo successful management. $\mathcal{F}$ Am Dent Assoc 1992;123:49-54

56 Kleinknecht RA, Mahoney ER, Alexander LD. Psychosocia and demographic correlates of temporomandibular disorders and related symptoms: an assessment of community and clinical findings. Pain 1987;29:313-24.

57 Dingman RO, Moorman WC. Meniscectomy in the treatment of lesions of the temporomandibular joint. F Oral Surg 1951;9:214-24.

58 Henny FA, Baldridge OL. Condylectomy for the persistently painful temporomandibular joint. $f$ Oral Surg 1957;15:24-31.

59 Rinchuse DJ, Abraham J, Medwid L, et al. TMJ sounds: are they a common finding or are they indicative of pathosis/dysfunction? Am f Orthod Dentofacial Orthop 1990;98:512-15.

60 Solberg WK, Hansson TL, Nordstrom B. The temporomandibular joint in young adults at autopsy: a morphologic classification and evaluation. f Oral Rehab 1985,12:303-21.

61 Kircos LT, Ortendahl DA, Mark AS, et al. Magnetic resonance imaging of the TMJ disk in asymptomatic volunteers. F Oral Maxillofac Surg 1987;45:852-4.

62 Gelb LN. FDA notifies physicians and patients about risks of TMJ implants. FDA Medical Bulletin 1991;21:2-3.

63 Gay JR, Abbott RH. Common whiplash injuries of the neck. FAMA 1953;152:1698-704.

64 Roydhouse RH. Whiplash and temporomandibular dysfunction. Lancet 1973;i:1394-5.

65 Lader E. Cervical trauma as a factor in the development of TMJ dysfunction and facial pain. Fournal of Craniomandibular Practice 1983;1:85-90.

66 Heise AP, Laskin DM, Gervin AS. Incidence of temporomandibular joint symptoms following whiplash injury. $\mathcal{F}$ Oral Maxillofac Surg 1992;50:825-8.

67 Pressman BD, Shellock FG, Schames J, et al. MR imaging of the temporomandibular joint abnormalities associated with cervical hyperextension hyperflexion (whiplash) injuries. $\mathcal{F}$ Magon Reson Immag 1992;2:569-74.

68 Brooke RI, Stenn PG. Postinjury myofascial dysfunction syndrome: its etiology and prognosis. Oral Surgery Oral Medicine Oral Pathology 1978;45:846-50.

69 Burgess J. Symptom characteristics of TMD in patients reporting blunt trauma and/or whiplash injury. 7 Craniomandib Disord Facial Oral Pain 1991;5:251-7.

70 Wall PD, Melzack R. Textbook of pain. Edinburgh: Churchill Livingstone, 1984:19-33,209-14.

71 Cooper BY, Sessle, BJ. Anatomy, physiology, and pathophysiology of trigeminal system paresthesias and dysesthephysiology of trigeminal system paresthesias and dysesthe1992;4:297-322.

72 Olin M. Components of complex TM disorders. $f$ Craniomandib Disord Facial Oral Pain 1990;4:193-6.

73 Howard RP, Benedict JV, Raddin JH, et al. Assessing neck extension-flexion as a basis for temporomandibular joint dysfunction. Fournal of Oral and Maxillofacial Surgery 1991; 49:1210-13.

74 Szabo TJ, Welcher JB, Anderson RD, et al. Human occupant kinematic response to low speed rear-end impacts. $S A E$ technicalpaper series 940532 1994;SP1045:23-35.

75 Ward CC, Szabo TJ, Welcher JB. Recent research on rear impact collisions. SAE technical paper series 3104540924 1994:1-8.

76 Weinberg LA, Lager LA. Clinical report on the etiology and diagnosis of TMJ dysfunction-pain syndrome. Fournal of Prosthetic Dentistry 1980;44:642-53.

77 Denucci DJ, Dionne RA, Dubner R. Identifying a neurobioogic basis for drug therapy in TMDs. F Am Dent Assoc 1996;127:581-93.

78 Nelson DA. Thoracic outlet syndrome "TOS" and dysfunction of the temporomandibular joint: proven pathology or pseudo-syndromes? Perspect Biol \& Med 1990;33:567-76.

79 Nelson DA. Coccydynia and lumbar disk disease-historical correlations and clinical cautions. Perspect Biol Med 1991;34:229-38.

80 Management of temporomandibular disorders. NIH Technol Assess Statement 1996;Apr 29-May 1:1-31. 